\title{
THE TREATMENT OF ASCARIS INFECTION WITH VELARDON
}

\author{
BY \\ J. H. P. JONXIS and H. BEKIUS \\ From the Children's Clinic, the University Hospital, Groningen, the Netherlands
}

(RECEIVED FOR PUBLICATION MARCH 18, 1953)

\begin{abstract}
Ascaris infection is still very common, mainly in children and especially in unhygienic conditions. In the human intestinal tract only that species of ascaris parasitic in man can develop. Every ascaris infection is caused by larvae from eggs which have been deposited in the soil with human faeces, and the ascaris egg must have developed for some time in the soil before it is capable of infecting another host. Direct infection by newly evacuated faeces is not possible. The absence of good water-closets and sewerage greatly increases the risk of infection, as also does the manuring of gardens with human faeces. It is obvious that under these conditions eating raw vegetables will almost certainly cause infection. Another source of infection is found in playgrounds for toddlers.
\end{abstract}

The complaints caused by ascaris vary and in many cases are vague. Not only do such symptoms as poor appetite, abdominal pain (often around the navel) and diarrhoea occur, caused by parasites in the intestinal tract, but also those connected with the passage of the larvae from the intestine through the liver to the lung and trachea causing as they pass bronchitis and transient lung infiltration. Eosinophilia, so often associated with ascaris infection, is suggestive of hypersensitivity. Other signs of allergy may be meningism, sterile meningitis, urticaria and pains in the joints. As long as the condition in the gastro-intestinal tract is normal, the worms give little trouble locally. However, as soon as the acidity of the duodenal content changes or there is a rise in temperature, the worms tend to migrate, causing various complications.

In combating ascaris, it is essential to prevent new infections. Good sewerage is one of the first conditions. In infected areas it is necessary to free as many ascaris carriers as possible of worms, not only as treatment but also to get rid of sources of infection. It should be borne in mind that in many cases a single course of treatment is not sufficient, even if all worms are expelled. In many cases the patient is also infested with larvae which are unaffected by treatment. In three or four weeks these have developed into new worms and the faeces will again contain eggs. It is often necessary, therefore, even if renewed infection is ruled out, to repeat the course of treatment with an interval of some weeks.

Oil of chenopodium in the correct dosage is the most potent anthelmintic. However, it is so toxic that it cannot be administered several times at short intervals to the same patient. Moreover, owing to its toxicity it is hardly suitable for mass treatment of entire infected groups of the population, a procedure which is highly desirable in the fight against ascaris. Santonin is less toxic but also far less effective, while a high dosage may cause reactions in the central nervous system. One of the first symptoms is a disturbance in colour vision. Hexylresorcinol is very active. It is far less toxic than oil of chenopodium and santonin. However, it is less suitable for children, since it has to be taken in capsules. The preparation itself causes damage to the mucosa of the mouth and oesophagus.

In spite of the use of anthelmintics and increased hygienic precautions, ascaris infection in man has been little reduced. The infection can be effectively combated only if an anthelmintic is available which is innocuous to the host of the parasite, so that administration may be repeated without causing untoward effects.

In some tropical regions papain was used as an anthelmintic as early as the seventeenth century, but so far apparently it has not been generally applied. Papain is the dried latex from the unripe fruit of Carica papaya. It contains an enzyme of the same name with a strongly proteolytic action, and in view of this property it is used for the production of protein hydrolysates. It affects the cuticula of the worm, causing the parasite to fall a victim to the intestinal juices. The shell of the eggs is also affected, so that they are rendered harmless. Since papain is innocuous to man, it is an almost perfect anthel- 
mintic, provided the concentration in the intestine is kept sufficiently high for some time.

In the children's clinic of the University Hospital at Groningen we have tested an anthelmintic of which the effect is based on the activity of papain.

Velardon (N. V. Organon, Oss.) is available in packages of $20 \mathrm{~g}$. granules containing $10 \mathrm{~g}$. of papain activated with $0.5 \mathrm{~g}$. of cysteine. The papain is standardized according to the method of Balls and Hoover (1937). The effect of papain on living ascarides is verified as follows. Papain suspensions are prepared in concentrations of $0.25 \%, 0.5 \%$, $1 \%$ and $2 \%$, and $50 \mathrm{ml}$. of each suspension is brought into contact with perhaps two living ascarides. The ascarides are first killed by the ferment, then disintegrated and finally dissolved.

The following table gives the results of this test: concentration of the papain and consequently reduce its activity. Moreover, the time during which the worm is in contact with the enzyme would be reduced. As a result of not administering a laxative. no dead worms will be found in the faeces in the majority of cases. They disintegrate in the intestinal canal. This applies partly also to worm eggs. damaged specimens of which may be found in the faeces.

Originally we gave a laxative after treatment. This caused evacuation of dead worms but the number of cases in which ascaris eggs continued to be found in the faeces was still fairly high. After a change in the method of treatment a marked improvement was observed.

Reappearance of eggs in the faeces five or six weeks after treatment does not imply that worms

\begin{tabular}{|c|c|c|c|c|c|c|}
\hline Batch & Concentration $(\bullet)$ & $30 \mathrm{Min}$. & 75 Min. & 2 Hours & 3 Hours & 4 Hours \\
\hline $811 / 51$ & 2 & Alive & - & $\begin{array}{l}\text { Some } \\
\text { corrosion }\end{array}$ & $\begin{array}{l}\text { Corrosion } \\
\text { continues }\end{array}$ & Dissolved \\
\hline Res. P. 236 & $\begin{array}{l}1 \\
0 \cdot 5 \\
0 \cdot 25\end{array}$ & $\begin{array}{l}\text { Alive } \\
\text { Alive } \\
\text { Alive }\end{array}$ & $\begin{array}{l}\text { Alive } \\
\text { Alive } \\
\text { Alive }\end{array}$ & $\begin{array}{l}\text { Alive } \\
\text { Alive }\end{array}$ & $\begin{array}{c}\text { Corrosion } \\
- \\
-\end{array}$ & $\begin{array}{l}\text { Dissolved } \\
\text { Corrosion } \\
\text { No corrosion } \\
\text { yet }\end{array}$ \\
\hline
\end{tabular}

As there is a high incidence of ascariasis in the northern provinces of the Netherlands, there was sufficient material for research. Treatment was given to those children who passed many ascarides in the faeces, most of whose histories suggested ascariasis. Several children had evacuated worms spontaneously. Others had a poor appetite and showed disturbances in absorption, and some abnormalities of the lungs for which no cause other than ascaris could be found. These complaints disappeared after treatment.

The result of treatment with 'velardon' was judged by the presence of ascaris eggs in the faeces in the first weeks after treatment, and if there was any doubt about the result, it was followed by a course of oil of chenopodium.

In order to reduce the contents of the intestine as far as possible at the beginning of treatment, an infusion of senna was given on the previous day, and during treatment the food intake was drastically reduced. The anthelmintic, consisting of $20 \mathrm{~g}$. granules containing an activated papain preparation, was administered to the fasting patient on the following morning. Children who are not able to take the full $20 \mathrm{~g}$. straight off can do so in small portions in the course of an hour. In the next four or five hours practically no food was given. Administration of the anthelmintic was not followed by a laxative. This is not necessary as the papain preparation is not toxic and the laxative would lower the were left in the intestine but is probably due to worms having developed from larvae which at the time of treatment were infesting the liver or spleen.

Altogether 20 children were treated, all under 8 years of age. All had numerous ascaris eggs in the faeces. Nine had spontaneously evacuated worms. Practically all had vague abdominal complaints which might have been due to ascaris infection. In six cases the complaints were so marked that the children were admitted to the clinic for ascariasis. In 15 cases the results were such that no more ascaris eggs were found in the faeces after a single course of treatment.

A course of treatment with oil of chenopodium with which we followed up this therapy to make quite certain of a cure, did not produce any more ascarides either, except in five cases. These were children in whom heavy infestation was suspected. In order to get an impression of the number of worms which had remained behind, they also were given a course of treatment with oil of chenopodium for three days three times as many drops as the number of years of the child's age.

The number of ascarides expelled was:

$\begin{array}{llr}\text { In the first patient } & \ldots & 50 \\ \text { In the second patient } & \ldots & 6 \\ \text { In the third patient } & \ldots & 21 \\ \text { In the fourth patient } & \ldots & \mathbf{4 5} \\ \text { In the fifth patient } & \ldots & 56\end{array}$

In Cases 3 and 5 eggs were still found in the faeces after this therapy. In Case 3 renewed 'velardon' 
therapy caused them to disappear. In Case 5 the second course of treatment with 'velardon' had to be followed by renewed therapy with oil of chenopodium, after which another 20 worms were evacuated. Tests on the faeces were still positive and a third course of 'velardon' treatment was needed.

These results show that it is possible in many cases to cure moderately infected children by a single course of treatment with this preparation. If the number of worms is very large the intestine is so filled with them that the concentration of the anthelmintic is too low to produce a conclusive result. The same applies to oil of chenopodium. In such cases repeated treatment is required. In view of its low toxicity, 'velardon' is very suitable for repeated therapy.

It is a remarkable fact that 'velardon' therapy of ascaris infection rarely causes evacuation of ascarides. The worms disintegrate entirely in the intestine. This does not, however, give rise to absorption of large quantities of toxic products. None of the children showed any reaction during treatment. Activated papain is, therefore, an excellent therapeutic agent against ascaris. It is not toxic and does not produce side-effects. Repeated treatment is required only in heavy infestations. However, the same applies to other anthelmintics.

In this investigation we have tried to form an opinion on 'velardon' as an anthelmintic in ascariasis only. Little attention was paid to its effect on other intestinal parasites, but we have the impression that good results might also be obtained in oxyuris infection.

\section{REFERENCE}

Balk, A. R. and Hoover, S. R. (1937). J. biol. Chem., 121, 737. 